\title{
A self-management measurement: Validity of the Partners in Health Scale (PHS) instrument in Peruvian elderly population
}

\author{
Isabel Peñarrieta-de Cordova*1, Carlos Francisco Albornoz-Jiménez², Tranquilina Gutiérrez-Gómez ${ }^{1}$, Rodrigo \\ León-Hernández ${ }^{3}$, David de Jesús Malibrán-Luque ${ }^{4}$, Ricardo Colmenares-Diaz ${ }^{4}$ \\ ${ }^{1}$ Tampico Nursing Faculty, Tamaulipas University-Mexico, Mexico \\ ${ }^{2}$ Universidad Privada Norbert Wiener in Lima, Peru \\ ${ }^{3}$ Universidad Autónoma de Tamaulipas, Mexico \\ ${ }^{4}$ Health Sciences, Faculty of Medicine "Dr. Alberto Romo Caballero" at Universidad Autónoma de Tamaulipas, Mexico
}

Received: July 1,2020

DOI: $10.5430 /$ jha.v9n4p20
Accepted: August 10, 2020

Online Published: August 18, 2020

\begin{abstract}
The Partners and Health Scale Instrument has been validated in several countries, however, it has just been applied in Spanishspeaking countries to people with chronic conditions, allowing a self-management evaluation with wide clinical application and research. It is the first time it has been applied in elderly patients (60 or older) in Spanish-speaking countries. This study shows the instrument validity in this population - users of health services of the Ministry of Health in Lima-Peru. An intentional non-probabilistic sample of 152 subjects with Construction Validity was performed: 1) Factor Analysis and 2) Confirmatory with structural equations and Reliability: Cronbach's Alpha presents construct validity in three factors with an explained variance of 0.597. From the results of the goodness of fit model measures obtained by AMOS 24.0 and FACTOR 10.10, it can be seen that 6 of the 7 measures obtained are acceptable. The reliability with the Cronbach Alpha coefficient was 0.845. Although the model may have high-quality goodness of fit, the possibility of another alternative model that meets a better fit cannot be rejected; the results allow us to conclude that this Instrument presents validity and reliability in the evaluation of self-management within three factors.
\end{abstract}

Key Words: Self-management, Validity, Elderly, Latin America, Chronicity

\section{INTRODUCTION}

More than $70 \%$ of the morbidity resulting from chronic conditions is suffered by those living in developing countries and $60 \%$ of them are people aged 60 or older. ${ }^{[1]}$ This group is characterized by the presence of multimorbidity, that is to say, two or more concomitant medical diagnoses. ${ }^{[2]}$

This leads to high use of medical services and long hos- pital stays, which leads to a loss of physical functioning, depression, polypharmacy, lower health-related quality of life (HrQoL), high symptom burden and high mortality in this group. ${ }^{[3]}$ Many of these problems can be prevented or delayed by healthy behaviors, such as avoiding smoking and drinking, promoting healthy diet, and getting regular physical activity. Even for people with diminished capacity or some chronic condition, this is only part of taking care of

*Correspondence: Isabel Peñarrieta-de Cordova; Email: decordova.maria.isabel@gmail.com; Address: Tampico Nursing Faculty, Tamaulipas University-Mexico, Mexico. 
themselves (self-management behavior). That's why it is recognized by the World Health Organization that healthy aging can be a reality for everyone. This requires a change in perspective to stop considering healthy as the absence of diseases, but instead promoting the functional capacity that enables older people to be and do what is valuable and right for them. Due to this, it is proposed to implement programs that promote self-management behavior of chronic conditions. $^{[4]}$

Self-management is still defined in different ways. The most frequently quoted is the one proposed by the Institute of Medicine: "tasks that individuals must undertake to live well with one or more chronic conditions. These tasks include having the confidence to deal with medical management, role management, and emotional management of their conditions." ${ }^{\text {[5] }}$ It is also recognized the variety of theoretical foundations cited in interventions and measurement tools.

From the results of a recent review of 28 interventions, eight reported no specific theoretical foundations, ten used Bandura's social cognitive theory as principle, while the rest provided a wide variety of other theoretical underpinnings, ${ }^{[6]}$ very few of them explicitly describe how this is conceptualized or even how to measure it directly ${ }^{[7,8]}$ let alone programs aimed at the elderly population.

It is reported that disease-specific measures are more numerous, while generic self-management measures are widely used. ${ }^{[6]}$ Three of the most commonly used generic measures are the Patient Activation Measure (PAM) ${ }^{[9]}$ the Health Partner Scale (HPS), ${ }^{[10]}$ and the Self-Efficacy Scale for Chronic Disease Management (CDMS).${ }^{[11]}$ A recent study aimed at assessing the structural and convergent validity of these three outcome measures suggested that the three tools had different measures but correlated constructs and confirmed the multidimensional concept for self-management in a sample of people with neurological disorders. Further research is still needed. ${ }^{[6-12]}$

One of the most reported programs in chronic condition management was developed at Flinders-Australia University, which conceptualizes self-management and measures this through the Partners in Health Instrument (PHS). The PIH concept describes 6 characteristics of this. ${ }^{[13]}$ These are: (1) Knowledge about the condition and treatment; (2) Participation in treatment decisions and health conditions; (3) Confidence and ability to access and use health care services; (4) Skills to monitor and respond to signs and symptoms; (5) Management of the impact of chronic conditions on emotional, social, and physical aspects; (6) Having an adequate lifestyle to avoid implementing behaviors that do not promote health.

Published by Sciedu Press
Robust self-management statistics can contribute to better care and services since identified needs can be met, while unidentified needs are left unmeasured and unmet. Therefore, personalized attention will advance through the creation of measures with the capacity to quantify and distinguish more aspects of self-management. Thus, the provider's ability to measure self-management domains must be rigorous. ${ }^{[14]}$

The fourth and final version of the PIH was published in $2016^{[13-15]}$ and this consists of 12 items with a numerical 8-point visual response format. It has the following interesting characteristics: (1) It is aimed at adults with a chronic condition; it is not specific to only one disease; (2) It is completed by self-report, allowing self-evaluation and also evaluation by a health provider; (3) It is short (12 items); (4) The psychometric properties are satisfactory. (5) It measures all self-management concept strategies, such as medical, cognitive/decision-making, emotional, and social strategies. ${ }^{[16,17]}$ A previous factor analysis identified four factors: knowledge, association in treatment, recognition, management of symptoms and coping. ${ }^{[15]}$

This instrument has also been validated in other contexts such as in China, ${ }^{[18]}$ France, ${ }^{[16]}$ and Holland ${ }^{[19]}$ where it was carried out in the elderly population (over 65 years of age). In Latin America - Peru and Mexico - it was used in populations with chronic diseases ${ }^{[20,21]}$ such as chronic kidney disease ${ }^{[22]}$ and hearing loss in older adults. ${ }^{[23]}$

Although all the studies recognize the psychometric and applicative validity of the instrument in the results, different dimensions or factors are reported depending on the population, which corroborates that this is a complex and multidimensional construction of self-management. ${ }^{[6-12]}$

Therefore, this study tries to contribute to this construction through the validation of the Partners in Health Scale in the elderly population in Peru. It is part of the project Network of Self-management in Chronic Diseases (www . reddeautom anejo.com) in which, together with the Ministry of Health and PAHO of that country, they carry out interventions that promote self-management in the elderly population. The results will also help professionals to introduce the concept of self-management to their patients and provide an evaluation of the self-management dimensions. This will help patients identify more precisely their needs, thus, assess the effectiveness of the interventions in this age group.

\section{MATERIALS AND METHODS}

The study carried out the following steps:

1) Construct validity: Factor Analysis

2) Confirmatory with structural equations 


\section{3) Reliability: Cronbach's Alpha}

\subsection{Population and sample}

Elderly users of the health services of the Ministry of Health in northern Lima-Peru.

\subsection{Inclusion criteria}

Older patients (60 or more years old) with at least one medically diagnosed chronic disease and with the ability to provide personal information, date, and location.

All older adults who attended the 7 health services were selected for a megaproject study of the Self-management Network by convenience sampling, which met the inclusion criteria and voluntarily agreed to participate in the study. The total sample included 152 elderly patients. Senior nursing students, previously trained, participated in the application of surveys and information capture as well.

\subsection{Measuring instruments}

A socio-demographic scale and Partners in Health Scale were used. The instrument was previously validated in an adult population with chronic conditions by this research team. ${ }^{[20,21]}$ It consists of 12 questions answered with a scale ranging from 0 to 8 points. The more points obtained the better self-management score; similarly, the fewer points the less self-management score.

For the statistical analysis the following steps were performed.

\subsection{Descriptive analysis}

In this analysis, the sociodemographic variables of the patients were evaluated.

\subsection{Instrument validation}

For the validation of the instrument, the sample size analysis was performed using SPSSS 25.0 with the Kaiser-MeyerOlkin sampling adequacy test (KMO), Bartlett's sphericity test and the value of the determinant. The Factorial Analysis was carried out with the Software Factor.10.10.01, the method of extraction of Robust Unweighted Least Squares (RULS) and the Direct Oblimin rotation method, discarding loads less than 0.35 . The structural analysis was conducted with AMOS 24.0 using Unweighted Least Squares and the covariances were analyzed by the Maximum Probability method. Then, with SPSS 25.0 and by using Cronbach's Alpha, the measurement of the instrument reliability and its factors were performed.

\section{ReSUlts}

The average age of the patients was 71 , mostly women $(69.7 \%)$, and $57.2 \%$ were also married. About $40.8 \%$ suf- fered from more than one chronic disease (see Table 1).

Table 1. Sociodemographic data of the sample

\begin{tabular}{|c|c|c|c|}
\hline \multirow{2}{*}{ Demographic aspects } & $f$ & \multicolumn{2}{|l|}{$\%$} \\
\hline & $(\mathrm{n}: 152)$ & \multicolumn{2}{|l|}{ (100) } \\
\hline Age & $\bar{X}: 71$ & Range: Min:60 & Max: 91 \\
\hline Education (years of study) & $\bar{X}: 6.3$ & Range: Min: 0 & Max: 21 \\
\hline \multicolumn{4}{|l|}{ Gender } \\
\hline Female & 106 & 69.7 & \\
\hline Male & 46 & 30.3 & \\
\hline \multicolumn{4}{|l|}{ Civil Status } \\
\hline Married & 87 & 57.2 & \\
\hline Widower & 40 & 26.3 & \\
\hline Divorced & 4 & 2.6 & \\
\hline Single & 19 & 12.5 & \\
\hline \multicolumn{4}{|l|}{ Family Type } \\
\hline Nuclear & 7 & 4.6 & \\
\hline Modified nuclear family & 14 & 9.2 & \\
\hline Reconstituted Nuclear Family & 7 & 4.6 & \\
\hline Extended & 62 & 40.8 & \\
\hline Partner & 8 & 5.3 & \\
\hline Atypical & 12 & 7.9 & \\
\hline Family members n. $^{\circ}$ & $\bar{X}: 5$ & Range: Min: 1 & Max: 13 \\
\hline \multicolumn{4}{|l|}{ Chronic diseases n. ${ }^{\circ}$} \\
\hline One & 90 & 59,2 & \\
\hline More than one & 62 & 40.8 & \\
\hline Years since the first diagnosis & $\bar{X}: 9$ & Range: Min: 1 & Max: 47 \\
\hline
\end{tabular}

Sample adequacy: Goodness of fit values are affected by the sample size, so it is recommended from 100 to 200 participants. $^{[24]}$

In this case, the sample size was 152 patients and the adequacy was verified to perform factor analysis. In Table 2, it can be seen that the three indicators are suitable to validate the sample size and to perform the factor analysis.

Factor Extraction: Table 3 shows the results obtained by the Factor 10.10.01 using the method of extracting Unweighted Robust Least Squares (RULS), with eigenvalues greater than 1. It can be seen that three factors were obtained, with an explained variance of 0.5797 .

Table 2. KMO test, Bartlett's test for sphericity and the determinant

\begin{tabular}{lll}
\hline \multicolumn{2}{l}{ Kaiser-Meyer-Olkin measurement of sampling adequacy } & 0.798 \\
\hline \multirow{3}{*}{ Bartlett's test for sphericity } & Chi-Squared & 640,222 \\
& gl & 66 \\
Dig. & 0.000 \\
Determinant & & 0.013 \\
\hline
\end{tabular}


Table 3. Variance explained based on eigenvalues

\begin{tabular}{cccc}
\hline Variable & Eigenvalues & $\begin{array}{c}\text { Variance } \\
\text { Proportion }\end{array}$ & $\begin{array}{c}\text { Variance Cumulative } \\
\text { Proportion }\end{array}$ \\
\hline 1 & 4.57056 & 0.38088 & 0.38088 \\
2 & 1.3415 & 0.11179 & 0.49267 \\
3 & 1.25599 & 0.10467 & 0.59734 \\
4 & 0.89511 & 0.07459 & \\
5 & 0.74813 & 0.06234 & \\
6 & 0.67392 & 0.05616 & \\
7 & 0.62466 & 0.05206 & \\
8 & 0.50563 & 0.04214 & \\
9 & 0.47009 & 0.03917 & \\
10 & 0.34617 & 0.02885 & \\
11 & 0.31363 & 0.02614 & \\
12 & 0.25462 & 0.02122 & \\
\hline
\end{tabular}

Table 4. Factor rotation matrix (absolute values less than 0.35 were omitted

\begin{tabular}{cccc}
\hline Variable & Factor 1 & Factor 2 & Factor 3 \\
\hline V1 & & & 0.561 \\
V2 & & & 0.638 \\
V3 & & & 0.832 \\
V4 & & 0.587 & \\
V5 & & 0.733 & \\
V6 & & & 0.418 \\
V7 & & & 0.41 \\
V8 & & & 0.375 \\
V9 & 0.661 & & \\
V10 & 0.738 & & \\
V11 & 0.582 & & \\
V12 & 0.588 & & \\
\hline
\end{tabular}

Factor Rotation: Table 4 shows the results obtained by Factor 10.10.01 using the Direct Oblimin rotation method. Loads lower than 0.35 were discarded.

Confirmatory analysis: Figure 1 shows the structural model using AMOS with the method of Unweighted Least Squares and the covariance analysis by the maximum likelihood method. Adjustments were made to the model with the modification of rates as suggested by AMOS. Factor 1 showed a maximum variance of 0.84 with variable 7 and the minimum variance was 0.46 with variable 6 . In factor 2 the minimum was 0.59 with variable 5 and in factor 3 it was 0.82 with variable 9 and the lowest was 0.55 with variable 11 .

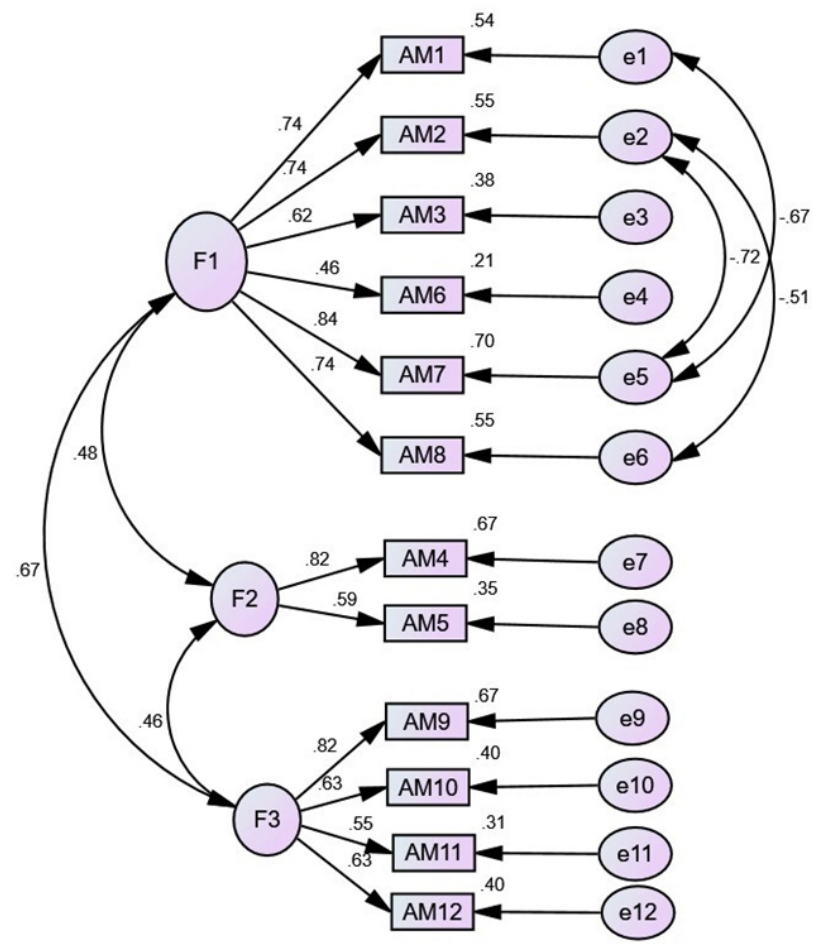

Figure 1. Result of the factor confirmation

Table 5 shows the results of the measures of goodness of fit of the model obtained by the AMOS and FACTOR. It can be seen that 6 of the 7 measures obtained are acceptable; consequently, it can be concluded that the model itself is adequate.

Table 5. Measures of goodness of fit of the model

\begin{tabular}{lcccc}
\hline Fit measure & $\begin{array}{c}\text { Acceptable } \\
\text { adjustment levels }\end{array}$ & Amos Output & Factor Output & $\begin{array}{c}\text { Acceptability level } \\
\text { obtained }\end{array}$ \\
\hline RMR & Close to 0 & 0.215 & Not calculated by the model & Low \\
GFI & $>0.90$ & 0.983 & 0.988 & Acceptable \\
AGFI & $>0.90$ & 0.972 & 0.976 & Acceptable \\
CFI & $>0.90$ & Not calculated by the model & 0.987 & Acceptable \\
RMSEA & $<0.05$ & Not calculated by the model & 0.052 & Acceptable \\
NFI & $>0.90$ & 0.968 & Not calculated by the model & Acceptable \\
\hline
\end{tabular}


Reliability analysis: Table 6 shows the results of the instrument reliability and factors. Only factor 2 had reliability under 0.7 and the instrument reliability was measured by a 0.845 Cronbach's alpha.

Table 6. Reliability of the final instrument and its factors

\begin{tabular}{lcc}
\hline Factor & Cronbach's Alpha & N. $^{\circ}$ of elements \\
\hline Factor 1 & 0.750 & 4 \\
Factor 2 & 0.655 & 2 \\
Factor 3 & 0.815 & 6 \\
Total & 0.845 & 12 \\
\hline
\end{tabular}

\section{Discussion}

The results show that the Partners in Health Scale Instrument in the Peruvian elderly population (from 60 or older) presents validity and reliability in the evaluation of self-management behavior.

The validity is demonstrated by the values of the goodness of fit indicators, the values of GFI, AGFI, CFI, and NFI exceed 0.90 as theoretically recommended by Rigo, Alaminos, and Molina. ${ }^{[25-27]}$ The RMSEA value corroborates the statement made by Veldman et al. ${ }^{[19]}$ and Xiaofei et al. ${ }^{[28]}$ and findings using the PIH in the Netherlands and China respectively $(<$ 0.08 ). The NFI and the IFC are similar to the findings of Petkov et al. ${ }^{[29]}$ (> 0.90) using the PIH in Australia. Likewise, the model is confirmed by the structural analysis where three factors are identified (see Figure 1).

The instrument reliability measured by the Cronbach's alpha coefficient was 0.845 ; similar to the one found by Xiaofei et al. ${ }^{[28]}$ in China with 0.865; Petkov et al. ${ }^{[29]}$ with 0.88 in Australia and Hudon et al. ${ }^{[16]}$ with 0.85 in France; Veldman et al. ${ }^{[19]}$ also reported values from 0.77 to 0.88 in the PIH factors in the Netherlands. On the one hand, it should be noted that this result corroborates the results obtained in Latin America, ${ }^{[20,21]}$ as well as the population in other contexts in which this instrument does have validity in the selfmanagement evaluation in people with chronicity. ${ }^{[16,18,19]}$ On the other hand, it is interesting to confirm that there are differences in the four dimensions identified in almost every study conducted with the original instrument. ${ }^{[15,29,30]}$ For instance, the case of the population in China with 3 dimensions, ${ }^{[18]}$ Holland with 2 dimensions, ${ }^{[19]}$ Mexico, and Peru with 3 dimensions. ${ }^{[20,21]}$

Specifically, in the case of validation in Peruvian adults with chronic conditions, there is a coincidence in the confrontational dimension (items 9, 10,11 and 12), but none in the knowledge dimension (items 1 and 2) as it occurs in the
Results in Peruvian adult population. In these results the aspects related to medical treatment are incorporated in addition to the knowledge items, such as complying with medical treatment, attending appointments or controls and recording or monitoring symptoms and responses to them when they get worse, (3, 6, 7 and 8); also identifying a new dimension (items 4 and 5) related to the relationship with providers and health system in sharing decisions and receiving services according to their culture or expectations. The possible explanations are the differences in the participants' education, the comorbidity, and the complexity of chronic diseases in this age group, which are also pointed out by other authors. ${ }^{[16]}$ Also, the complexity of this self-management is a complex, multi-dimensional and changing process. ${ }^{[6,12]}$ According to these results, the instrument comprises three dimensions: management of the medical condition (items 1, 2, 3, 6, 7, 8), participation dimension within the health system (items 4 , 5) and management or coping (items 9, 10, 11, 12) of the impact of their condition (physical, emotional and social).

We consider that these dimensions, even if they have items in a different order, are not all excluded from the statistical result; therefore, they maintain the characteristics of the selfmanagement concept according to its original version ${ }^{[15,29,30]}$ and other authors' versions of self-management. ${ }^{[31,32]}$ These characteristics are:

1) Knowledge about the condition and treatment. 2) Participation in treatment decisions and health conditions. 3) Confidence and ability to access and use health services. 4) Skills in the supervision and response of signs and symptoms. 5) Management of the impact of their chronic condition on emotional and social physical aspects. 6) Having an adequate lifestyle to avoid implementing behaviors that do not promote health.

Another benefit of this instrument is that, in addition to being used as a tool to evaluate the self-management from the perspective of the person in chronicity, it can also be used by a health provider to contrast differences between their results and the patients', as in the case of the Flinders Program, where this instrument is another tool that integrates the Program. ${ }^{[33]}$ It allowed us to analyse collaboratively these discrepancies or areas that show weaker characteristics on self-management and should be addressed by the person.

\section{Strengths AND Limitations}

\subsection{Strengths}

The study was conducted in the health services users' population in the first level of care of the Ministry of Health. This population was very similar to other users of these health facilities in Lima, consequently it is a more representative 
sample for this population.

The study was conducted rigorously, taking into account the adequate training of the interviewers, the process in applying the surveys, the statistical analysis of the instrument Validity and Reliability with the appropriate software, and the recommended indicators of goodness of fit of the model found. Moreover, the data capture was verified by checking the database and results analysis by two research teams.

The study participants had time to answer before and after their appointment since the interviewers accompanied them to their homes in case the survey was not finished, or either they agreed to complete the survey at another time. The participants had no qualms about participating in the study. There were no unanswered questions, nor did they refuse to answer them.

\subsection{Limitations}

The population is not representative of elderly adults from culturally different regions other than those in Lima and with a specific educational level. It is suggested carrying out greater validations in other contexts, such as mountains and forests, as well as in a population with a higher educational level.

\section{Conclusions}

The results allow us to guarantee the validity and reliability of the instrument Partners and Health Scale (PHS) in three factors within the Peruvian elderly population in chronicity.

\section{CONFlicts of InTEREST Disclosure}

The authors declare they have no conflicts of interest.

\section{REFERENCES}

[1] WHO: Aging and Health. Report, Data and Numbers [Internet]. Geneva: World Health Organization; c2018 [cited 2020 July 1st]. Available from: https://www.who.int/es/news-room/fact -sheets/detail/envejecimiento-y-salud

[2] Eckerblad J, Waldréus N, Johansson-Stark A, et al. Symptom management strategies used by older community-dwelling people with multimorbidity and a high symptom burden - a qualitative study. BMC Geriatr. 2020; 20: 210. PMid: 32539798. https://doi.or $\mathrm{g} / 10.1186 / \mathrm{s} 12877-020-01602-\mathrm{y}$

[3] Eckerblad J, Theander K, Ekdahl A, et al. Symptom burden in community-dwelling older people with multimorbidity: a crosssectional study. BMC Geriatr. 2015; 15(1): 1. PMid: 25559550. https://doi.org/10.1186/1471-2318-15-1

[4] WHO: World Report on Aging and Health [Internet]. Geneva: World Health Organization; c2015 [cited 2020 July 1st]. Available from: https://apps.who.int/iris/bitstream/handle/10665/1 86466/9789240694873_spa.pdf; jsessionid=F56D57E813B BF1C40E7C85881B493210? sequence $=1$

[5] Packer TL, Fracini A, Audulv A, et al. What we know about the purpose, theoretical foundation, scope and dimensionality ofexisting self-management measurement tools: A scoping review. Patient Educ Couns. 2018; 101(4): 579-595. https://doi.org/10.101 6/j.pec.2017.10.014 PMid:29239734

[6] Kephart G, Packer TL, Audulv Å, et al. The structural and convergent validity of three commonly used measures of self-management in persons with neurological conditions. Qual Life Res. 2018. https: //doi .org/10.1007/s11136-018-2036-8 PMid:30390217

[7] Audulv Å, Ghahari S, Kephart G, et al. The Taxonomy of Everyday Self-management Strategies (TEDSS): A framework derived from the literature and refined using empirical data. Patient Educ Couns. 2018; 102: 367-375. https://doi.org/10.1016/j.pec. 2018 .08.034 PMid:30197252

[8] Jonkman NH, Schuurmans MJ, Jaarsma T, et al. Self-management interventions: Proposal and validation of a new operational definition. J. Clin. Epidemiol. 2016; 80: 34-42. https ://doi.org/10.1016/ j.jclinepi.2016.08.001 PMid:27531245
[9] Hibbard JH, Mahoney ER, Stockard J, et al. Development and testing of a short form of the patient activation measure. Health Serv Res. 2005; 40(6 Pt 1): 1918-1930. https://doi.org/10.1111/j.14 75-6773. 2005.00438 . x PMid:16336556 PMCid:PMC1361231

[10] Smith D, Harvey P, Lawn S, et al. Measuring chronic condition self-management in an Australian community: Factor structure of the revised Partners in Health (PIH) scale. Qual Life Res. 2017; 26(1): 149-159. https://doi.org/10.1007/s11136-016-136 8-5 PMid:27432251

[11] Lorig K, Chastain RL, Ung E, et al. Development and evaluation of a scale to measure perceivedself-efficacy in people with arthritis. Arthritis Rheum. 1989; 32(1): 37-44. https://doi.org/10.100 2/anr.1780320107 PMid:2912463

[12] Packer TL, Fracini A, Audulv A, et al. What we know about the purpose, theoretical foundation, scope and dimensionality of existing self-management measurement tools: A scoping review. Patient Educ Couns. 2018; 101(4): 579-595. https://doi.org/10.101 6/j.pec.2017.10.014 PMid:29239734

[13] Battersby M, Harris M, Smith D, et al. A pragmatic randomized controlled trial of the Flinders Program of chronic condition management in community health care services. Patient Educ Couns. 2015; 98(11): 1367-1375. https://doi.org/10.1016/j.pec.2015.0 6.003 PMid:26146240

[14] Shand L, Higgins R, Murphy B, et al. Development and validation of the Healthcare Providers Patient-Activation Scale. Patient Educ Couns. 2019; 102: 1550-1557. https://doi.org/10.1016/j.pe c. 2019.03.005 PMid:30885404

[15] Smith D, Harvey P, Lawn S, et al. Measuring chronic condition self-management in an Australian community: factor structure of the revised Partners in Health (PIH) scale. Qual Life Res. 2016; 26(1): 149-159. https://doi.org/10.1007/s11136-016-136 8-5 PMid:27432251

[16] Hudon É, Chouinard MC, Krieg C, et al. The French adaptation and validation of the Partners in Health (PIH) scale among patients with chronic conditions seen in primary care. PLoS One. 2019; 14(10): e0224191. https://doi.org/10.1371/journal.pone .0224191 PMid:31644561 PMCid:PMC6808494 
[17] Miller WR, Lasiter S, Bartlett Ellis R, et al. Chronic disease selfmanagement: A hybrid concept analysis. Nurs Outlook. 2015; 63(2): 154-161. https://doi.org/10.1016/j.outlook.2014.07.00 5 PMid:25241136 PMCid:PMC4326608

[18] Chiu TML, Tam KTW, Siu CF, et al. Validation study of a Chinese version of Partners in Health in Hong Kong (C-PIH HK). Qual Life Res. 2016; 26(1): 199-203. https://doi.org/10.1007/s11136 -016-1315-5 PMid:27216940

[19] Veldman K, Reijneveld SA, Lahr MMH, et al. The Partners in Health scale for older adults: design and examination of its psychometric properties in a Dutch population of older adults. Health Expect. 2016; 20(4): 601-607. https://doi.org/10.1111/hex.12488 PMid:27714892 PMCid:PMC5512997

[20] Peñarrieta MI, Barrios FF, Gutierrez-Gomes T, et al. Selfmanagement in chronic conditions: partners in health scale instrument validation. J. Nurs. Manag. 2014; 20(10): 32-37. https://do i. org/10.7748/nm2014.02.20.10.32.e1084 PMid:24571163

[21] Peñarrieta MI, Vergel O, Schmith L, et al. Validation of an instrument to evaluate self-management in chronic diseases at the first level of health care. Rev Cient de Enferm. 2012; VIII(1): 64-73. Available from: http://reddeautomanejo.com/assets/articulo-pub licado-validacion-peru.pdf

[22] Baxter C, Morello A, Smith D, et al. A preliminary investigation of the Partners in Health scale measurement properties in patients with end stage renal disease. Aust J Prim Health. 2017; 23(3): 288. https://doi .org/10.1071/PY16095 PMid:28076747

[23] Convery E, Meyer C, Keidser G, et al. Assessing hearing loss self-management in older adults. Int. J. Audiol. 2018; 57(4): 313-20.. DOI: https://doi.org/10.1080/14992027.2017.13 90268 PMid:29081257

[24] Ruiz MA, Pardo A, Martín RS. Structural equation models. Papeles Del Psicol. 2010; 31(1): 34-45. Available from: http://www. cop. es/papeles

[25] Alaminos A, Francés FJ, Penalva C, et al. Introduction to structural models in social research. Cuenca: University of cuenca PYDLOS
Editions; 2015. 160. Available from: http://dspace.ucuenca.e du.ec/handle/123456789/23457

[26] Rigo D, Donolo D. Structural equation models. Uses in psychological and educational research. Interam J Psychol. 2018; 52(3): 345-57. https://doi.org/10.30849/ripijp.v52i3.388

[27] Mi-Kyeong J, Jung-Won A, Yeon-Hwan P, et al. Validity and Reliability of the Korean Version of the Partners In Health Scale (PIH-K). J Korean Crit Care Nurs. 2019; 12(2): 1-12. https: //doi.org/10.34250/jkccn.2019.12.2.1

[28] Xiaofei Z, Hui F, Lawn S, et al. Translation and initial psychometric evaluation of the Chinese version of the partners in health scale. Biomed Res. 2017; 28(16): 7322-9. Available from: http://www. biomedres.info/biomedical-research/translation-and -initial-psychometric-evaluation-of-the-chinese-v ersion-of-the-partners-in-health-scale-8268.html

[29] Petkov J, Harvey P, Battersby M. The internal consistency and construct validity of the partners in health scale: validation of a patient rated chronic condition self-management measure. Qual Life Res. 2010; 19(7): 1079-1085. https://doi.org/10.1007/s11136-0 10-9661-1 PMid:20437206

[30] Battersby MW, Ask A, Reece MM, et al. The Partners in Health scale: The development and psychometric properties of a generic assessment scale for chronic condition self-management. Aust J Prim Health. 2003; 9(3): 41-52. https ://doi .org/10.1071/PY03022

[31] Corbin J, Strauss A. Managing chronic illness at home: Three lines of work. Qual. Sociol. 1985; 8(3): 224-247. https ://doi.org/10 $.1007 / \mathrm{BF} 00989485$

[32] Lorig KR, Holman H. Self-management education: history, definition, outcomes, and mechanisms. Ann Behav Med. 2003; 26: 1-7. Available from: https://doi.org/10.1207/S15324796ABM26 01_01 PMid:12867348

[33] FLIN: Flinders Program Manual. [Internet]. Adelaide: Flinders University; c2016 [cited 2020 July 1st]. Available from: https://www.flindersprogram.com.au/wp-content/upl oads/Flinders-Program-Information-Paper.pdf 